\title{
OPERATOR VERSIONS OF SHANNON TYPE INEQUALITY
}

\author{
ISMAIL NIKOUFAR
}

Abstract. In this paper, we present some refinements and precise estimations of parametric extensions of Shannon inequality and its reverse one given by Furuta in Hilbert space operators. We also demonstrate an extension of operator Shannon type inequality.

Mathematics subject classification (2010): Primary 47A63; Secondary 46L05, 46L60.

Keywords and phrases: Operator inequality, Operator Shannon type inequality, relative operator entropy, generalized relative operator entropy.

\section{REFERENCES}

[1] P. Belavkin And P. Staszewski, $C^{*}$-algebraic generalization of relative entropy and entropy, Ann. Inst. H. Poincare Sect. A, 37 (1982), 51-58.

[2] R. Bhatia, Matrix Analysis, Springer-Verlag, 1996.

[3] R. Clausius, Ueber die bewegende Kraft der Wärme und die Gesetze, welche sich daraus für die Wärme selbst ableiten lassen, Annalen der Physik, 79 (1850), 368-397, 500-524, doi:10.1002/andp.18501550403,

[4] A. Ebadian, I. Nikoufar And M. Eshagi Gordi, Perspectives of matrix convex functions, Proc. Natl. Acad. Sci., 108(18) (2011), 7313-7314.

[5] E. G. EFFros, A matrix convexity approach to some celebrated quantum inequalities, Proc. Natl. Acad. Sci. U S A., 106(4) (2009), 1006-1008.

[6] E. G. EfFros And F. Hansen, Non-commutative perspectives, Ann. Funct. Anal., 5(2) (2014), 74 79.

[7] T. FURUTA, Parametric extensions of Shannon inequality and its reverse one in Hilbert space operators, Linear Algebra Appl., 381 (2004) 219-235.

[8] T. FURUTA, Reverse inequalities involving two relative operator entropies and two relative entropies, Linear Algebra Appl., 403 (2005), 24-30.

[9] J. I. FUJII AND E. KAMEI, Relative operator entropy in noncommutative information theory, Math. Japonica, 34 (1989), 341-348.

[10] S. FURUICHI, K. YANAGI, K. KURIYAMA, A note on operator inequalities of Tsallis relative operator entropy, Linear Algebra Appl., 407 (2005) 19-31.

[11] F. Hansen And G. Pedersen, Jensen's operator inequality, Bull. London Math. Soc., 35 (2003), 553-564.

[12] F. Hansen And G. Pedersen, Jensen's inequality for operators and Lowner's Theorem, Math. Ann., 258 (1982), 229-241.

[13] H. Lieb AND M. B. Ruskai, Proof of the strong subadditivity of quantum-mechanical entropy, J. Math. Phys., 14 (1973) 1938-1941.

[14] G. Lindblad, Entropy, information and quantum measurements, Comm. Math. Phys., 33 (1973), 305-322.

[15] N. F. G. Martin And J. W. England, Mathematical theory of entropy, Foreword by James K. Brooks. Reprint of the 1981 hardback edition. (English) Cambridge: Cambridge University Press. xii, 2011.

[16] I. NikoufaR, On operator inequalities of some relative operator entropies, Adv. Math., 259, (2014), 376-383.

[17] I. NiKoUfaR, A perspective approach for characterization of Lieb concavity theorem, to appear in Demonstratio Math., (2016). 
[18] M. NAKamura And H. Umegaki, A note on the entropy for operator algebra, Proc. Jpn. Acad., 37 (1961), 149-154.

[19] K. Yanagi, K. Kuriyama AND S. Furuichi, Generalized Shannon inequalities based on Tsallis relative operator entropy, Linear Alg. Appl., 394, (2005), 109-118. 